\title{
Pengaruh Variasi Konstanta Pegas dan Massa Roller CVT Terhadap Performa Honda Vario $150 \mathrm{cc}$
}

\author{
Irvan Ilmy dan I Nyoman Sutantra \\ Departemen Teknik Mesin, Fakultas Teknologi Industri, Institut Teknologi Sepuluh Nopember (ITS) \\ e-mail: tantra@me.its.ac.id
}

\begin{abstract}
Abstrak-Perkembangan dunia otomotif khususnya sepeda motor terus dikembangkan untuk mendapatkan kenyamanan dalam pengendalian. Produsen otomotif khususnya roda dua (sepeda motor) telah memproduksi kendaraan yang memakai sistem transmisi otomatis yang disebut dengan CVT (Continuously Variable Transmission).Tujuan dari tugas akhir ini untuk membandingkan nilai gaya dorong, kecepatan maksimum, percepatan maksimum kendaraan yang dihasilkan masing-masing pegas dan roller CVT, dan mencari pegas dan roller CVT terbaik untuk performa kendaraan. Pengujian ini menggunakan empat pegas CVT dan empat roller CVT dengan nilai konstanta dan berat yang berbeda. Pengujian dilakukan dengan memasang masing-masing pegas dan roller CVT pada kendaraan dan mengambil data melalui proses dynotest. Output dari pengujian dynotest adalah nilai daya, torsi, dan putaran mesin yang dihasilkan kendaraan. Dari data tersebut dikonversi menjadi nilai gaya dorong dan kecepatan kendaraan. Untuk memperoleh kecepatan maksimum kendaraan, perlu dilakukan perhitungan gaya hambat akibat gesekan ban dengan jalan dan gaya hambat akibat udara. Dari nilai gaya dorong, gaya hambat, dan massa kendaraan dapat diketahui nilai percepatan kendaraan. Pegas KTC 2000 rpm (k=31,59 N/mm) mampu menghasilkan gaya dorong kendaraan terbesar. Roller CVT dengan 18 gram mampu menghasilkan kecepatan maksimum senilai 128,29 km/jam. Pegas KTC $2000 \mathrm{rpm}$ ( $k=31,59 \mathrm{~N} / \mathrm{mm}$ ) cocok digunakan untuk berakselerasi di jalan kota dan jalan lurus. Variasi roller 18 gram cocok digunakan untuk berakselerasi di jalan luar kota karena menghasilkan kecepatan maksimum paling besar. Roller 18 gram juga cocok digunakan di kedua medan jalan karena mampu menghasilkan kecepatan maksimum tertinggi.
\end{abstract}

Kata Kunci-Continuously Variable Transmission (CVT), Pegas CVT, Roller CVT, Dynotest.

\section{PENDAHULUAN}

$\mathrm{P}$ ERKEMBANGAN dunia industri dan teknologi otomotif mengalami kemajuan yang sangat pesat. Sepeda motor adalah salah satu produk otomotif yang terus dikembangkan oleh produsen karena merupakan alat transportasi yang banyak digunakan oleh masyarakat khususnya di Indonesia..

Saat ini produk kendaraan roda dua (sepeda motor) telah dilengkapi sistem transmisi otomatis. Jenis transmisi otomatis yang digunakan adalah Continuously Variable Transmission (CVT). Sepeda motor dengan sistem transmisi otomatis ini lebih praktis dalam pemakaian dibandingkan dengan sepeda motor bertransmisi manual, dikarenakan pengendara tidak perlu merubah transmisi kecepatan kendaraannya secara manual, tetapi secara otomatis berubah sesuai dengan putaran mesin, sehingga cocok digunakan di daerah perkotaan yang macet maupun trek panjang luar kota.

CVT terdiri dari puli primer atau driver pulley dan puli sekunder atau driven pulley yang dihubungkan dengan $v$-belt. Pada pulli primer terdapat speed governor yang berperan merubah besar kecilnya diameter puli primer yang didalamnya terdapat 6 buah roller sentrifugal yang akan menerima gaya sentrifugal akibat putaran crankshaft. Oleh karena itu roller sentrifugal akan terlempar keluar menekan bagian dalam sisi pulli yang dapat bergeser (sliding sheave) ke arah sisi puli tetap (fixed sheave) sehingga menyebabkan terjadinya perubahan diameter pulli primer, yaitu membesar atau mengecil.

Besar kecilnya gaya tekan roller sentrifugal terhadap pulli bergerak ini berbanding lurus dengan berat roller sentrifugal dan putaran mesin. Semakin berat roller sentrifugal semakin besar gaya dorong roller sentrifugal terhadap pulli bergerak. Sedangkan pada pulli sekunder pergerakan pulli diakibatkan oleh tekanan pegas. Puli sekunder ini hanya mengikuti gerakan sebaliknya dari puli primer. Jadi berat roller dan tekanan pegas sangat berpengaruh terhadap rasio diameter puli primer dan puli sekunder.

Mengacu pada tugas akhir maupun penelitian yang sudah dilakukan sebelumnya yaitu tentang pengaruh konstanta pegas CVT pada kendaraan Honda Scoopy 110 cc serta pengaruh berat roller CVT pada kendaraan Honda Scoopy 110 cc, maka dalam pembahasan tugas akhir ini, komponen CVT yang akan dianalisa adalah pegas yang terletak pada puli sekunder dan roller pada kendaraan berbeda yaitu kendaraan berjenis skuter matik Honda Vario $150 \mathrm{cc}$. Ada berbagai macam varian pegas dan roller CVT yang dapat digunakan untuk memperoleh performa optimal pada Honda Vario $150 \mathrm{cc}$. Maka dari itu perlu dilakukan analisa pegas dan roller CVT dengan nilai yang tepat sehingga dapat menghasilkan performa optimal pada Honda Vario $150 \mathrm{cc}$. 


\section{URAIAN PENELITIAN}

\section{A. Sistem transmisi otomatis}

Transmisi otomatis adalah transmisi kendaraan yang pengoperasiannya dilakukan secara otomatis berdasarkan prinsip gaya sentrifugal dan gaya gesek yang terjadi pada komponen-komponennya. Transmisi otomatis umumnya digunakan pada sepeda motor jenis scooter (skuter). Transmisi otomatis atau Continuously Variable Transmission (CVT) merupakan mekanisme transmisi yang terdapat dua buah pulley yang dihubungkan dengan sabuk ( $v$-belt) untuk memperoleh rasio gigi yang bervariasi. Perubahan rasio berlangsung secara otomatis dengan cara mengubah diameter puli primer dan puli sekunder. Dengan sendirinya perubahan kecepatan dapat berlangsung secara halus dan berkesinambungan dengan putaran mesin. Konstruksi CVT secara umum ditunjukkan pada gambar 1, dimana pulley utama yaitu driver pulley dan driven pulley dihubungkan oleh $v$-belt untuk mentransmisikan tenaga dari engine.

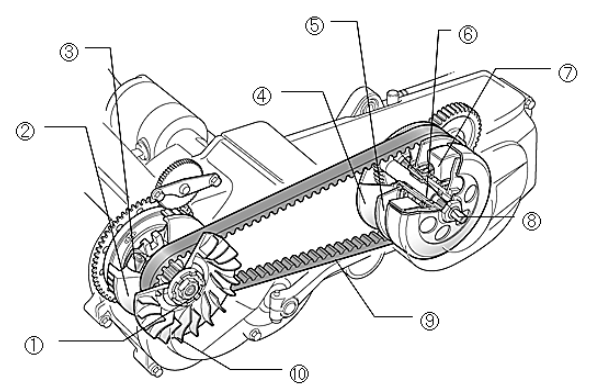

Gambar 1. Konstruksi CVT [1].

Keterangan:

1. Poros Engkol

2. Pulley penggerak primer

3. Roller

4. Pulley tetap sekunder

5. Pulley penggerak sekunder

6. Batang penggerak gear primer

7. Clutch carrier

8. V-belt

9. Pulley tetap primer

\section{B. Analisa gaya pada driven pulley akibat tekanan pegas}

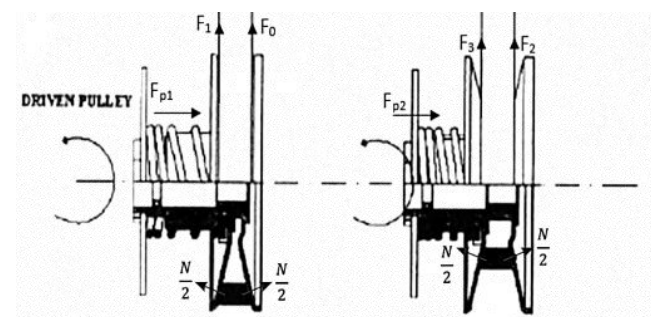

Gambar 2. Gaya-gaya yang Bekerja pada Driven Pulley [2].

Pada gambar 2 dapat dilihat bahwa gaya yang melawan dari Moveable Driven Pulley adalah gaya dari pegas yang besarnya dapat dirumuskan sebagai berikut :

$$
\text { Fpegas }=\mathrm{K} .\left(\mathrm{x}_{1}-\mathrm{x}_{0}\right)
$$

$$
\begin{array}{ll}
\text { Fpegas } & \text { : Gaya Pegas }(\mathrm{N}) \\
\mathrm{x}_{1} & \text { : Panjang awal }(\mathrm{m})
\end{array}
$$

$\mathrm{x}_{0} \quad$ : Panjang akhir (m)

Besar dari konstanta pegas divariasikan dan $\left(\mathrm{x}_{1}-\mathrm{x}_{0}\right)$ adalah perubahan jarak dari pegas yang terjadi akibat diberi beban $\mathrm{F}$ pegas tertentu.
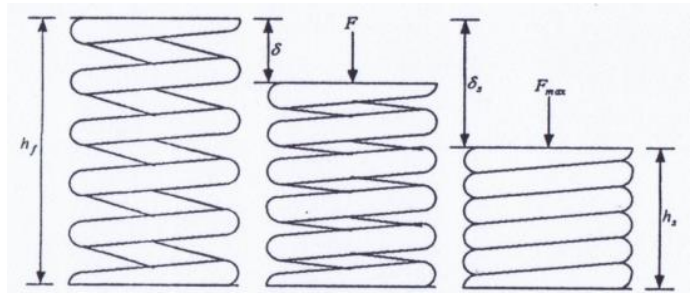

Gambar 3. Kondisi Pegas Dengan Beban Kerja [3].

Konstanta pegas (k) dapat ditentukan dari persamaan berikut:

$$
\mathrm{k}=\frac{F}{\delta}=\frac{d^{4} G}{8 D^{3} N a}
$$

dimana:

G : modulus geser material

$\delta \quad:$ defleksi pegas (m)

F : beban kerja

$\mathrm{Na}$ : lilitan aktif

$\mathrm{K} \quad$ : konstanta pegas

Gaya dorong kendaraan didefinisikan sebagai kemampuan kendaraan untuk dipercepat, dan mengatasi hambatanhambatan yang terjadi, diantaranya hambatan rolling ban (rolling resistance), hambatan aerodinamis, dan hambatan tanjakan. Kemampuan kendaraan tersebut sangat dipengaruhi oleh kemampuan mesin kendaraan dan pemilihan tingkat serta rasio transmisi (it), efisiensi transmisi $(\eta t)$ dan radius roda kendaraan (r) seperti pada persamaan 3 berikut.

$$
F t=\frac{T \theta \cdot i t \cdot i g \cdot n t}{r}
$$

Dari karakteristik torsi mesin $\left(\mathrm{T}_{\mathrm{e}}\right)$, diketahui bahwa torsi sebagai fungsi dari putaran mesin. Putaran dari mesin menentukan kecepatan dari kendaraan. Sehingga, karakteristik torsi mesin sebagai fungsi dari kecepatan kendaraan. Adapun hubungan kecepatan dan putaran mesin dapat dirumuskan pada persamaan 4 berikut.

$$
V=\frac{n \theta_{0} 2 \pi y}{\text { it } \operatorname{ig} .60}(1-S)
$$

Semakin mudah kendaraan dipercepat pada setiap kecepatan maka semakin bagus gaya dorong kendaraan tersebut. Besarnya percepatan tergantung pada besarnya massa kendraan (M), gaya dorong kendaraan $(\mathrm{Ft})$, hambatan aerodinamis (Ra), dan hambatan rolling (Rr). Besarnya percepatan kendaraan pada jalan datar dirumuskan pada persamaan berikut (2.10) 


$$
\begin{aligned}
a & =\frac{F t-R a-R r}{\gamma m \mathrm{M}} \\
\gamma_{\mathrm{m}} & =1,04+0,0025 .\left(\mathrm{i}_{0}\right)^{2} \\
\mathrm{i}_{0}= & \mathrm{it} . \mathrm{ig}
\end{aligned}
$$

\section{Gaya hambat kendaraan}

Hambatan rolling adalah gaya hambat pada ban akibat defleksi arah vertikal pada saat berputar. Faktor ini juga sangat mempengaruhi performa kendaraan saat bergerak. Jika gesekan antara permukaan ban dan jalan semakin kecil maka hal ini juga mempengaruhi performa kendaraan. Nilai gaya hambat ini dipengaruhi oleh koefisien hambatan rolling (fr), massa kendaraan (m), dan percepatan gravitasi (g) seperti pada persamaan berikut.

$\mathrm{Rr}=\mathrm{fr} . \mathrm{m} \cdot \mathrm{g}$

$\mathrm{fr}=\mathrm{f}_{0}+\mathrm{f}_{\mathrm{s}}\left(\frac{\mathrm{V}}{100}\right)^{2,5}$

Nilai $\mathrm{f}_{0}$ dan $\mathrm{f}_{\mathrm{s}}$ bergantung pada tekanan ban kendaraan yang dapat diketahui dari persamaan berikut:

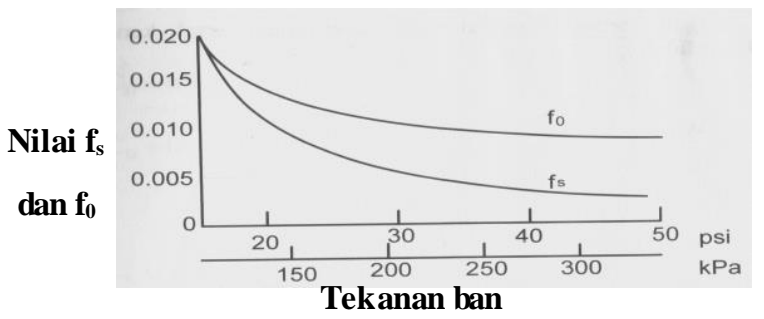

Gambar 4. Pengaruh Tekanan ban pada $\mathrm{f}_{\mathrm{s}}$ dan $\mathrm{f}_{0}$ [4].

Hambatan Aerodinamis adalah gaya hambat yang terjadi berlawanan arah dengan kendaraan secara. Nilai gaya hambat dipengaruhi oleh koefisien aerodynamic resistance $(\mathrm{Cd})$, densitas udara $(\rho)$, kecepatan kendaraan $(V)$, dan luas frontal kendaraan (Af) seperti pada persamaan 11 berikut

$$
\mathrm{Ra}=1 / 2 \cdot \rho \cdot \mathrm{Cd} \cdot \mathrm{V}^{2} \cdot \mathrm{A}_{\mathrm{f}}
$$

Tabel 1.

Koefisien Aerodynamic Resistance Kendaraan

\begin{tabular}{lc}
\hline \multicolumn{1}{c}{ Jenis Kendaaraan } & Koefisien Hambat \\
\hline Kendaraan penumpang & $0,3-0,6$ \\
Kendaraan convertible & $0,4-0,65$ \\
Kendaraan balap & $0,25-0,3$ \\
Bus & $0,6-0,7$ \\
Truck & $0,8-1,0$ \\
Tractor - trailer & $0,8-1,3$ \\
Sepeda motor + pengendara & 1,8 \\
\hline \hline
\end{tabular}

\section{METODE PENELITIAN}

Tahap awal dari penelitian ini adalah dilakukan studi literatur, yaitu dengan merumuskan permasalahan dan mengkaji permasalahan tersebut. Kajian bisa dilakukan melalui buku, jurnal, dan penelitian-penelitian terdahulu. Tahap kedua adalah penentuan jenis kendaraan sebagai obyek penelitian. Setelah diperoleh data kendaraan melalui pengujian, maka akan dilakukan analisa pengaruh dari keempat macam pegas dan roller continuous variable transmission (CVT) terhadap performa kendaraan.

\section{A. Studi literatur}

Tabel 2.

Spesifikasi Kendaraan Honda Vario 150 [10]

\begin{tabular}{|l|l|}
\hline Diameter x Langkah & $57,3 \times 57,9 \mathrm{~mm}$ \\
\hline Volume Langkah & $149,3 \mathrm{cc}$ \\
\hline Perbandingan Kompresi & $10,6: 1$ \\
\hline Daya Maksimum & $9,3 \mathrm{KW} / 8500 \mathrm{rpm}$ \\
\hline Torsi Maksimum & $12,8 \mathrm{~N} \cdot \mathrm{m} / 5000 \mathrm{rpm}$ \\
\hline Starter & Pedal \& Elektrik \\
\hline Sistem Bahan Bakar & Injeksi (PGM-FI) \\
\hline Tipe mesin & 4 langkah, SOHC berpendingin cairan \\
\hline Kapasitas Tangki & 5,5 liter bahan bakar \\
\hline Rasio Final Drive & $10,6: 1$ \\
\hline Transmisi & Otomatis, V-matic \\
\hline Kelistrikan & Baterai 12 V - 5 Ah (tipe MF) \\
\hline Lampu depan & LED 2,6 W x 2 (low); 5,2 W x 2 (high) \\
\hline Sistem pengapian & Full transisterize, baterai \\
\hline Panjang x Lebar x Tinggi & $1.921 \times$ x 683 x 1.096 mm \\
\hline Jarak Sumbu Roda & 1.280 mm \\
\hline Jarak Terendah ke Tanah & 135 mm \\
\hline Curb Weight & $109 \mathrm{~kg}$ \\
\hline Tipe Rangka & Tulang punggung \\
\hline Tipe Suspensi Depan & Teleskopik \\
\hline Tipe Suspensi Belakang & Lengan Ayun, Shockbreaker Tunggal \\
\hline Ukuran Ban Depan & $80 / 90$ - 14M/C 40P (tanpa ban dalam) \\
\hline Ukuran Ban Belakang & $90 / 90$ - 14M/C 46P (tanpa ban dalam) \\
\hline Rem Depan & Cakram Hidrolik, Piston Tunggal \\
\hline
\end{tabular}

\section{B. Menentukan nilai konstanta pegas CVT}

Tabel 3.

Penentuan nilai konstanta pegas

ORI
\begin{tabular}{|c|c|c|c|}
\hline $\mathrm{m}(\mathrm{kg})$ & $\mathrm{F}(\mathrm{N})$ & $\times(\mathrm{mm})$ & $\mathrm{k}(\mathrm{N} / \mathrm{mm})$ \\
\hline 0 & 0 & 0 & 0 \\
\hline 6 & 58,86 & 2,7 & 21,8 \\
\hline 8 & 78,48 & 3,3 & 23,78182 \\
\hline 13,2 & 129,492 & 5 & 25,8984 \\
\hline 19 & 186,39 & 6,2 & 30,0629 \\
\hline
\end{tabular}

$1000 \mathrm{rpm}$
\begin{tabular}{|c|c|c|c|}
\hline $\mathrm{m}(\mathrm{kg})$ & $\mathrm{F}(\mathrm{N})$ & $\times(\mathrm{mm})$ & $\mathrm{k}(\mathrm{N} / \mathrm{mm})$ \\
\hline 0 & 0 & 0 & 0 \\
\hline 6 & 58,86 & 2,9 & 20,29655 \\
\hline 8 & 78,48 & 3,5 & 22,42286 \\
\hline 13,2 & 129,492 & 5,2 & 24,90231 \\
\hline 19 & 186,39 & 6,3 & 29,58571 \\
\hline
\end{tabular}

$1500 \mathrm{rpm}$
\begin{tabular}{|c|c|c|c|}
\hline $\mathrm{m}(\mathrm{kg})$ & $\mathrm{F}(\mathrm{N})$ & $\times(\mathrm{mm})$ & $\mathrm{k}(\mathrm{N} / \mathrm{mm})$ \\
\hline 0 & 0 & 0 & 0 \\
\hline 6 & 58,86 & 2,4 & 24,525 \\
\hline 8 & 78,48 & 3,1 & 25,31613 \\
\hline 13,2 & 129,492 & 4,8 & 26,9775 \\
\hline 19 & 186,39 & 6,1 & 30,55574 \\
\hline
\end{tabular}

$2000 \mathrm{rpm}$
\begin{tabular}{|c|c|c|c|}
\hline $\mathrm{m}(\mathrm{kg})$ & $\mathrm{F}(\mathrm{N})$ & $\times(\mathrm{mm})$ & $\mathrm{k}(\mathrm{N} / \mathrm{mm})$ \\
\hline 0 & 0 & 0 & 0 \\
\hline 6 & 58,86 & 2,2 & 26,75455 \\
\hline 8 & 78,48 & 2,8 & 28,02857 \\
\hline 13,2 & 129,492 & 4,5 & 28,776 \\
\hline 19 & 186,39 & 5,9 & 31,59153 \\
\hline
\end{tabular}

Menentukan konstanta pegas dilakukan dengan memberikan pembebanan dengan massa yang bervariasi yaitu, $6 \mathrm{~kg}, 8 \mathrm{~kg}$, $13,2 \mathrm{~kg}$ dan $19 \mathrm{~kg}$. Selanjutnya besar kekakuan pegas dihitung dengan menggunakan rumus $k=\frac{F}{x}$ dimana $F$ merupakan gaya yang diberikan dan $x$ merupakan defleksi dari panjang pegas awal dikurangi panjang pegas setelah dikenai pembebanan. Nilai konstanta pegas yang didapatkan dari hasil pengujian dengan pembebanan terbesar yaitu $30,06 \mathrm{~N} / \mathrm{mm}$ untuk pegas orisinil, 29,56 N/mm untuk pegas $1000 \mathrm{rpm}, 30,56 \mathrm{~N} / \mathrm{mm}$ untuk pegas $1500 \mathrm{rpm}$ dan 31,59 N/mm untuk $2000 \mathrm{rpm}$. 


\section{Pengujian dan pengambilan data}

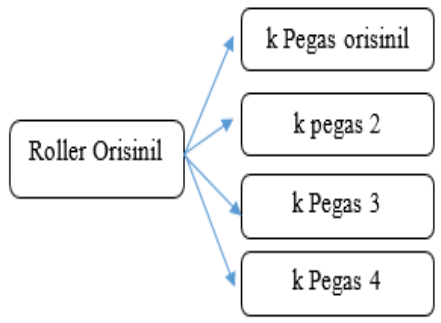

(a)

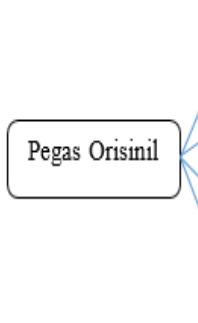

m Roller orisinit

m Roller 2

$\mathrm{m}$ Roller 4 (b)

Gambar 5. Skema Pengujian kendaraan dengan (a) variasi pegas dan (b) variasi roller.

Adapun variasi roller yang digunakan dalam pengujian adalah roller dengan massa 9 gram, 12 gram, 15 gram (roller orisinil) dan roller 18 gram. Sedangkan pegas CVT yang digunakan adalah pegas CVT dengan merk pasar KTC 1000 rpm, $1500 \mathrm{rpm}$ dan $1500 \mathrm{rpm}$

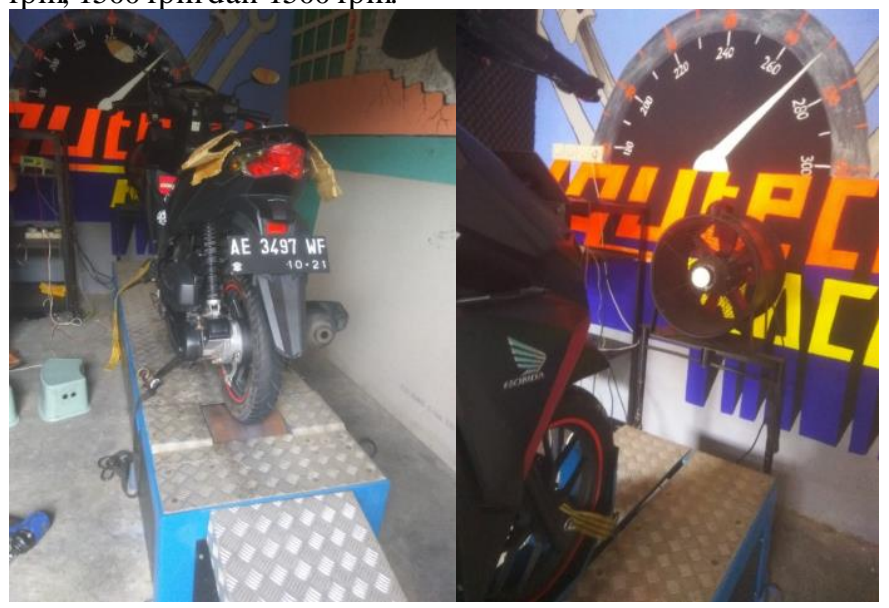

Gambar 6. Set-up pengujian dynotest.

Gambar 6 Menunjukkan set-up pengujian dynotest yang dilakukan di bengkel Iquteche Racing. Set-up kendaraan ini digunakan untuk setiap variasi dari pegas dan roller CVT dimana pengujian dilakukan langsung pada kendaraan, dimana roda belakang mengalami kontak langsung dengan roller dyno .

Proses pengujian dynotest ini dilakukan dengan menahan ban depan serta sisi kanan dan kiri dari kendaraan sebagai sistem keamanan pengujian. blower diletakkan di bagian depan kendaraan sebagai simulasi gaya hambat udara pada kendaraan. Pada prosedur pengujian kondisi ban diharapkan dalam keadaan masih bagus dengan tekanan ban standar. Diharapkan tidak terjadi slip antara roda dengan roller alat uji dynotest.

\section{HASIL DAN PEMBAHASAN}

A. Analisa pengaruh variasi massa roller CVT

1) Perbandingan gaya dorong kendaraan setiap roller CVT
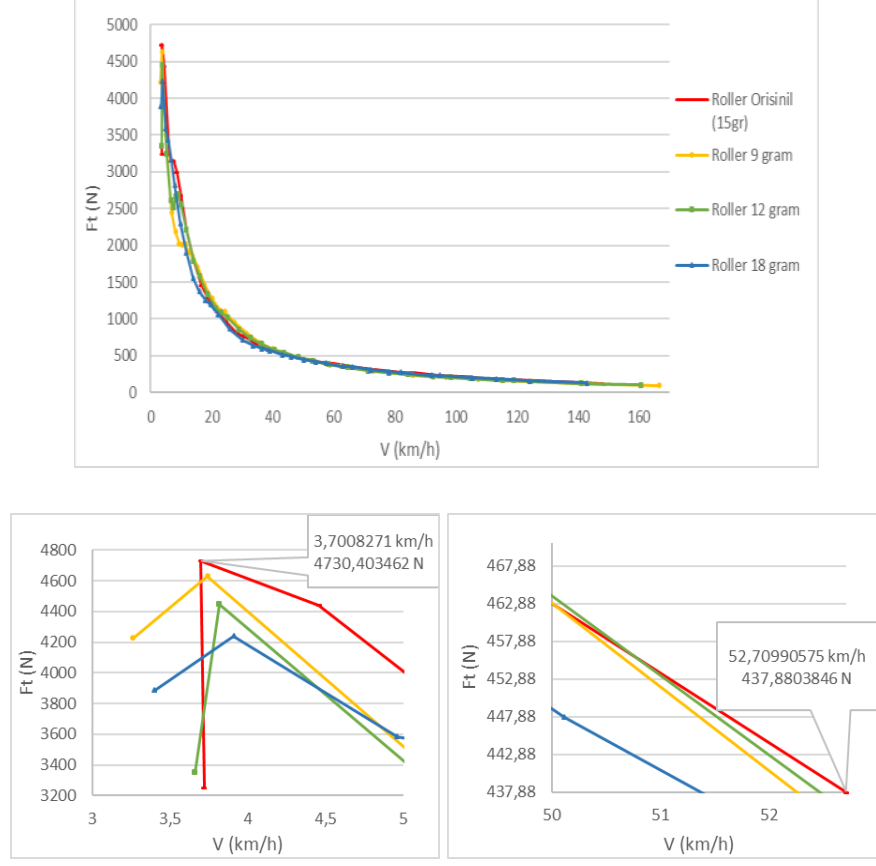

Gambar 7. Gaya Dorong Kendaraan (a) pada Kecepatan Rendah dan (b) pada Kecepatan Tinggi

Pada gambar 7, Nilai gaya dorong kendaraan merupakan hasil konversi nilai torsi dari hasil uji dyno dimana $F t=\frac{T \theta_{0} \text { it } \cdot \text { ig }}{r}$. Nilai kecepatan kendaraan merupakan konversi dari putaran mesin yang diperoleh dari proses uji dyno, dimana $V=\frac{\text { ne } 2 \pi \cdot y}{\text { it } i g \cdot 60}$.

Dengan klasifikasi bahwa kecepatan rendah pada $0 \mathrm{~km} / \mathrm{jam}$ sampai $50 \mathrm{~km} / \mathrm{jam}$ dan kecepatan tinggi diatas $50 \mathrm{~km} / \mathrm{jam}$, maka dari keempat pengujian pegas standar dengan variasi berat roller, nilai gaya dorong maksimum kendaraan terbesar mampu dihasilkan roller 15 gramyaitu senilai $4730,40 \mathrm{~N}$ pada kecepatan $3,70 \mathrm{~km} / \mathrm{jam}$ dan mampu menghasilkan nilai gaya dorong terbesar pada kecepatan rendah. Roller 15 gram juga menghasilkan nilai gaya dorong terbesar pada kecepatan tinggi. Nilai yang dihasilkan senilai 437,89 N.

2) Kecepatan maksimum kendaraan varian roller 18 gram

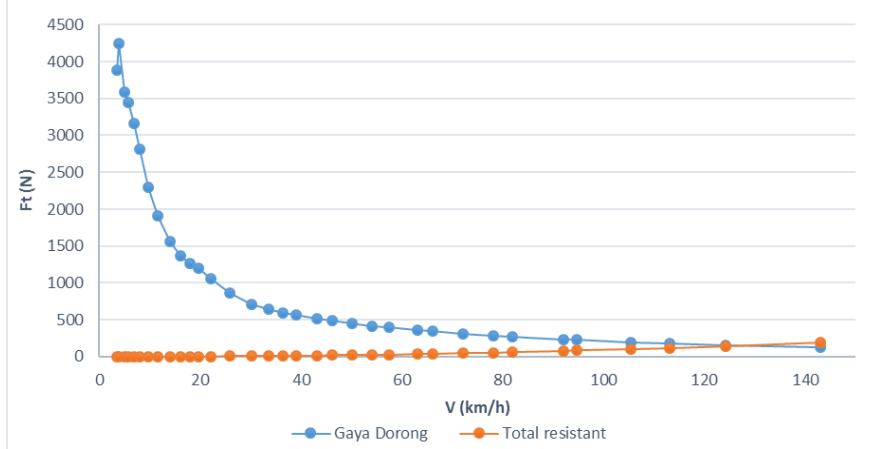

Gambar 8. Gaya dorong kendaraan dengan pengaruh gaya hambat.

Nilai gaya hambat udara dipengaruhi oleh densitas udara, koefisien drag, luas frontal kendaraan dan pengendara, serta 
kecepatan relatif udara dan kendaraan $\left(R a=1 / 2 \cdot \rho \cdot C_{D} \cdot V^{2} \cdot A_{f}\right)$. Dari kedua trendline grafik pada gambar 4.10 diperoleh nilai kecepatan maksimum yang dicapai kendaraan.

Nilai kecepatan maksimum diperoleh dari titik potong antara trendline grafik gaya dorong kendaraan dan gaya hambat udara. Titik potong ini berarti nilai gaya dorong kendaraan sama dengan gaya hambat udara terhadap kendaraan. Sehingga pada kecepatan dimana terdapat titik potong tersebut merupakan kecepatan maksimum kendaraan atau saat percepatan kendaraan sama dengan nol. Pada gambar 8 terlihat kecepatan maksimum kendaraan senilai 128,29 km/jam.

3) Perbandingan Percepatan Kendaraan dengan Variasi Roller CVT
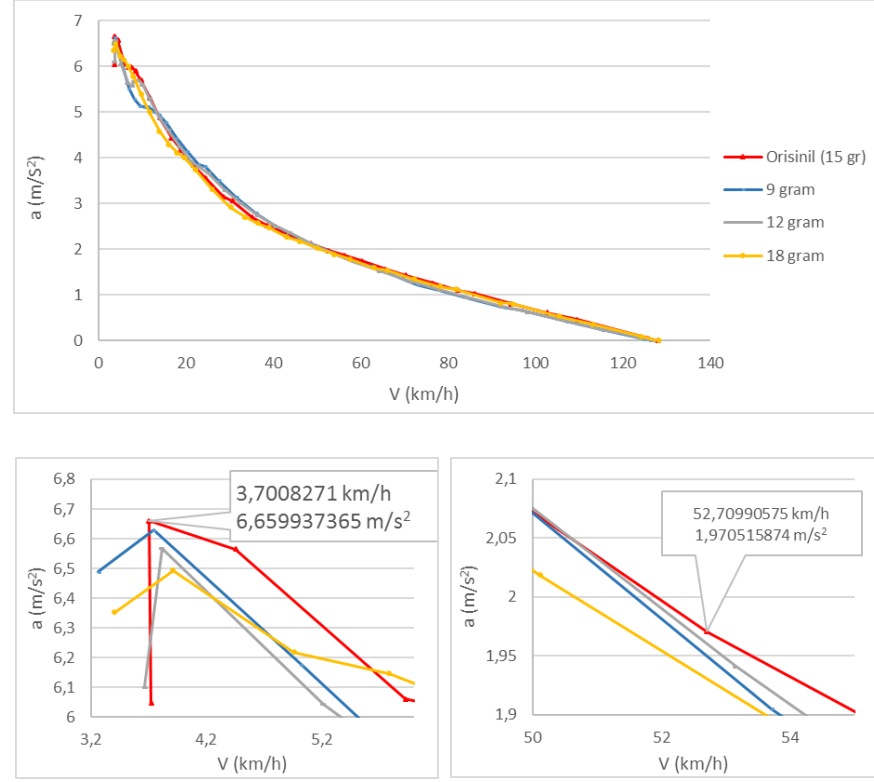

Gambar 9. Grafik perbandingan percepatan tiap roller CVT

Nilai percepatan kendaraan dipengaruhi oleh nilai gaya dorong kendaraan, gaya hambat rolling, gaya hambat udara, massa kendaraan dan pengemudi, serta faktor massa dari komponen kendaraan yang berotasi $a=\frac{F t-R Q-R Y}{\mathrm{~m} \cdot \gamma \mathrm{rm}}$.

Dengan klasifikasi bahwa kecepatan rendah pada $0 \mathrm{~km} / \mathrm{jam}$ sampai $50 \mathrm{~km} / \mathrm{jam}$ dan kecepatan tinggi diatas $50 \mathrm{~km} / \mathrm{jam}$, maka dari keempat varian roller dapat diketahui bahwa roller orisinil (15 gram) mampu menghasilkan nilai percepatan maksimum kendaraan pada kecepatan rendah yaitu sebesar $6,66 \mathrm{~m} / \mathrm{s}^{2}$ pada kecepatan 3,70 $\mathrm{km} / \mathrm{jam}$. Roller orisinil juga mampu menghasilkan nilai percepatan terbesar pada kecepatan tinggi. Nilai percepatan kendaraan yang dihasilkan oleh roller 15 gram tersebut senilai $1,97 \mathrm{~m} / \mathrm{s}^{2}$ pada kecepatan $52,71 \mathrm{~km} / \mathrm{jam}$.

\section{B. Analisa pengaruh variasi pegas CVT}

1) Perbandingan gaya dorong kendaraan setiap pegas CVT

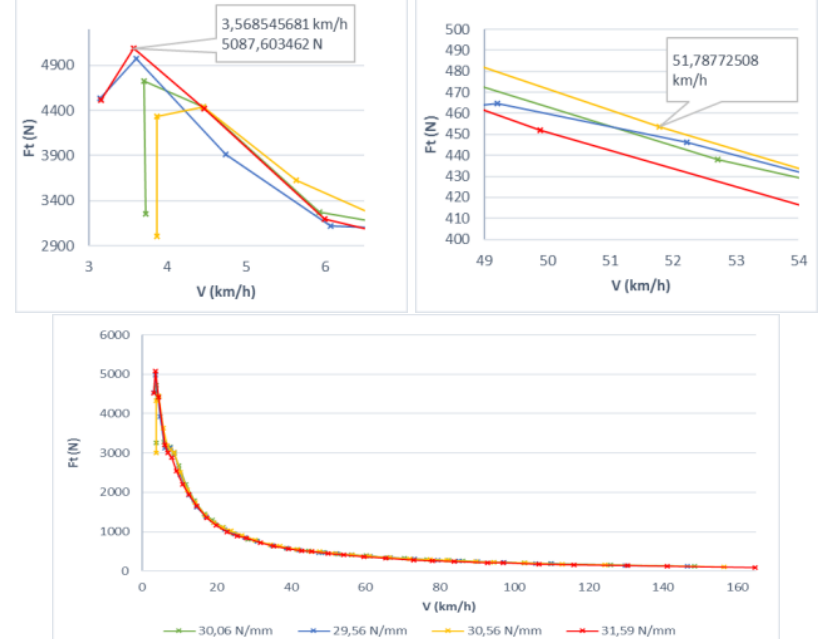

Gambar 10. Gaya dorong kendaraan. (a) pada Kecepatan Rendah dan (b) pada Kecepatan Tinggi.

Pada gambar 10, Nilai gaya dorong kendaraan merupakan hasil konversi nilai torsi dari hasil uji dyno dimana $F t=\frac{T \omega \cdot \text { it. ig }}{r}$. Nilai kecepatan kendaraan merupakan konversi dari putaran mesin yang diperoleh dari proses uji dyno, dimana $V=\frac{n e \cdot 2 \pi \cdot 5}{\text { it } i g \cdot 60}$.

Dengan klasifikasi bahwa kecepatan rendah pada $0 \mathrm{~km} / \mathrm{jam}$ sampai $50 \mathrm{~km} / \mathrm{jam}$ dan kecepatan tinggi diatas $50 \mathrm{~km} / \mathrm{jam}$, maka dari keempat pengujian kendaraan terbesar mampu dihasilkan oleh pegas $31,59 \mathrm{~N} / \mathrm{mm}$ yaitu senilai $5087,6 \mathrm{~N}$ pada kecepatan $3,57 \mathrm{~km} / \mathrm{jam}$ sehingga menghasilkan nilai gaya dorong terbesar pada kecepatan rendah. Sedangkan, pegas 30,56 N/mm mampu menghasilkan nilai gaya dorong terbesar pada kecepatan tinggi. Nilai gaya dorong kendaraan yang dihasilkan pegas $30,56 \mathrm{~N} / \mathrm{mm}$ senilai 453,61 $\mathrm{N}$ pada kecepatan

2) Kecepatan maksimum kendaraan varian Pegas 30,56 $\mathrm{N} / \mathrm{mm}$

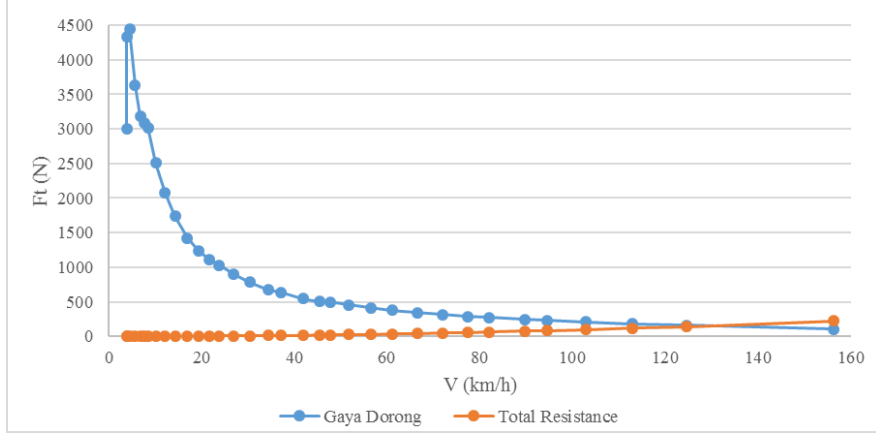

Gambar 11. Gaya dorong kendaraan dengan pengaruh gaya hambat.

Nilai gaya hambat udara dipengaruhi oleh densitas udara, koefisien drag, luas frontal kendaraan dan pengendara, serta kecepatan relatif udara dan kendaraan $\left(\mathrm{Ra}=1 / 2 \cdot \rho \cdot \mathrm{C}_{\mathrm{D}} \cdot \mathrm{V}^{2} \cdot \mathrm{A}_{\mathrm{f}}\right)$. Dari kedua trendline grafik pada gambar 4.10 diperoleh nilai kecepatan maksimum yang dicapai kendaraan.

Nilai kecepatan maksimum diperoleh dari titik potong antara trendline grafik gaya dorong kendaraan dan gaya hambat 
udara. Titik potong ini berarti nilai gaya dorong kendaraan sama dengan gaya hambat udara terhadap kendaraan. Sehingga pada kecepatan dimana terdapat titik potong tersebut merupakan kecepatan maksimum kendaraan atau saat percepatan kendaraan sama dengan nol. Pada gambar 4.15 terlihat kecepatan maksimum kendaraan senilai 128,22 km/jam.

3) Perbandingan Percepatan Kendaraan setiap Pegas
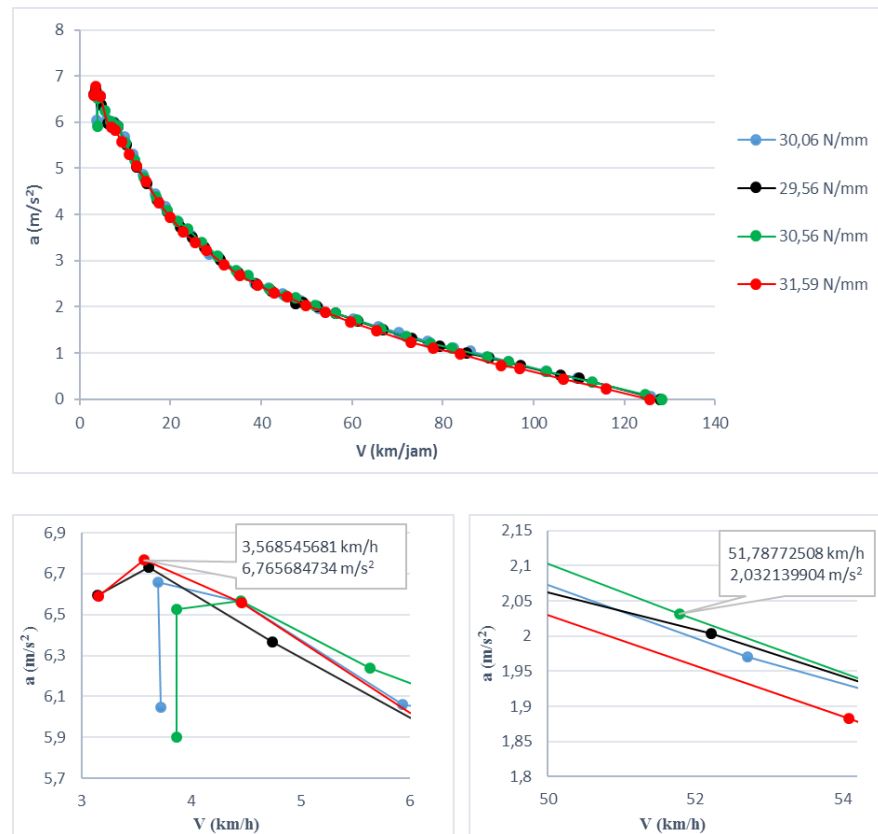

Gambar 12. Grafik Perbandingan Percepatan Kendaraan. (a) Pada Kecepatan Rendah dan (b) Pada Kecepatan Tinggi.

Nilai percepatan kendaraan dipengaruhi oleh nilai gaya dorong kendaraan, gaya hambat rolling, gaya hambat udara, massa kendaraan dan pengemudi, serta faktor massa dari komponen kendaraan yang berotasi $a=\frac{F t-R a-R y}{\mathrm{~m} \cdot{ }_{\mathrm{\gamma}} \mathrm{m}}$.

Dengan klasifikasi bahwa kecepatan rendah pada $0 \mathrm{~km} / \mathrm{jam}$ sampai $50 \mathrm{~km} / \mathrm{jam}$ dan kecepatan tinggi diatas $50 \mathrm{~km} / \mathrm{jam}$. Nilai percepatan maksimum kendaraan terbesar dihasilkan oleh pegas $31,59 \mathrm{~N} / \mathrm{mm}$ yaitu senilai $6,77 \mathrm{~m} / \mathrm{s}^{2}$ pada kecepatan 3,57 $\mathrm{km} / \mathrm{jam}$ sehingga menghasilkan nilai percepatan terbesar pada kecepatan rendah. Pegas 30,56 N/mm mampu menghasilkan nilai percepatan terbesar pada kecepatan tinggi. Nilai percepatan sebesar $2,03 \mathrm{~m} / \mathrm{s}^{2}$ pada kecepatan $51,79 \mathrm{~km} / \mathrm{jam}$.

\section{KESIMPULAN}

1. Pegas CVT dengan konstanta 31,59 N/mm mampu menghasilkan gaya dorong kendaraan terbesar pada kecepatan rendah senilai 5087,6 $\mathrm{N}$ dan pegas $30,56 \mathrm{~N} / \mathrm{mm}$ menghasilkan gaya dorong kendaraan terbesar pada kecepatan tinggi senilai 453,61 N.

2. Roller CVT dengan berat 18 gram mampu menghasilkan kecepatan maksimum senilai 128,29 km/jam. Pada saat kendaraan mengalami kecepatan maksimum maka tidak akan terjadi percepatan $(\mathrm{a}=0)$.

3. Pegas CVT dengan konstanta $31,59 \mathrm{~N} / \mathrm{mm}$ menghasilkan nilai percepatan kendaraan terbesar pada kecepatan rendah senilai $6,77 \mathrm{~m} / \mathrm{s} 2$ dan pegas CVT dengan konstanta 30,56 $\mathrm{N} / \mathrm{mm}$ menghasilkan nilai percepatan kendaraan terbesar pada kecepatan tinggi senilai $2,06 \mathrm{~m} / \mathrm{s} 2$

4. Dari masing-masing variasi pegas CVT dan roller CVT, pegas $31,59 \mathrm{~N} / \mathrm{mm}$ yang mampu menghasilkan gaya dorong kendaraan terbesar pada kecepatan rendah lebih cocok digunakan untuk berakselerasi di jalan kota. Sedangkan variasi roller 18 gram lebih cocok digunakan untuk berakselerasi di jalan luar kota karena mampu menghasilkan kecepatan maksimum paling besar dibanding varian pegas dan roller lainnya. Di sisi lain, roller 18 gram juga cocok digunakan di kedua medan jalan karena mampu menghasilkan kecepatan maksimum tertinggi walaupun nilai gaya dorong dan percepatan kendaraan maksimum yang dihasilkan tidak lebih baik dari varian pegas dan roller lainnya.

\section{DAFTAR PUSTAKA}

PT. Yamaha Motor Manufacturing, "Continuously Variable Transmission [Power Point Slides]," 2015.

[2] Wijanarko, "Analisa Pengaruh Perubahan Massa Roller Penggerak Variator Pulley Pada Continuously Variable Transmission (CVT) Terhadap Kinerja Traksi Pada Sepeda Motor Yamaha Mio," Surabaya, 2007.

[3] dan B. S. Sutantra, I Nyoman, Teknologi Otomotif, Edisi Kedua. Surabaya: Guna Widya, 2010. 